\title{
Correction to: Sexual Consent Perceptions of a Fictional Vignette: A Latent Growth Curve Model
}

\author{
Malachi Willis ${ }^{1} @$. Kristen N. Jozkowski ${ }^{2}$
}

๑) Springer Science+Business Media, LLC, part of Springer Nature 2022

\section{Correction to: Archives of Sexual Behavior https://doi.org/10.1007/s10508-021-02048-y}

The entries in the Consent Cue column of Table 1 are incorrect in the article as originally published, and so the information in the other columns of the table was mis-identified.

The original article has been corrected.

Publisher's Note Springer Nature remains neutral with regard to jurisdictional claims in published maps and institutional affiliations.

The original article can be found online at https://doi.org/10.1007/ s10508-021-02048-y.

\section{Malachi Willis}

malachi.willis@gla.ac.uk

1 MRC/CSO Social and Public Health Sciences Unit, Institute of Health and Wellbeing, University of Glasgow, Glasgow G12 8QQ, UK

2 Department of Applied Health Science, School of Public Health, and the Kinsey Institute for Research in Sex, Gender, and Reproduction, Indiana University, Bloomington, IN, USA 